\title{
Conservative Treatment in Grisel's Syndrome Following Tonsillectomy
}

\section{Youssouf Sogoba1, Abdoulaye Barry², Issa Amadou³, Boubacar Sogoba1, Drissa Kanikomo1, Seybou Hassane Diallo4, Oumar Coulibaly ${ }^{1}$, Youssoufa Maiga ${ }^{4}$, Siaka Soumaoro ${ }^{5}$, Dianguina dit Noumou Soumaré6, Kadidiatou Singaré5, Mohamed Keita ${ }^{5}$}

\author{
${ }^{1}$ Department of Neurosurgery, Hôpital Gabriel Touré, Bamako, Mali \\ ${ }^{2}$ Department of Pediatrics, Hôpital de Kati, Bamako, Mali \\ ${ }^{3}$ Department of Pediatric Surgery, Hôpital Gabriel Touré, Bamako, Mali \\ ${ }^{4}$ Department of Neurology, Hôpital Gabriel Touré, Bamako, Mali \\ ${ }^{5}$ Department of ENT, Hôpital Gabriel Touré, Bamako, Mali \\ ${ }^{6}$ Department of Pneumonology, Hôpital du Point G, Bamako, Mali \\ Email: sogobayoussouf@yahoo.fr
}

How to cite this paper: Sogoba, Y., Barry, A., Amadou, I., Sogoba, B., Kanikomo, D., Diallo, S.H., Coulibaly, O., Maiga, Y., Soumaoro, S., dit Noumou Soumaré, D., Singaré, K. and Keita M. (2018) Conservative Treatment in Grisel's Syndrome Following Tonsillectomy. World Journal of Neuroscience, 8, 38-43.

https://doi.org/10.4236/wjns.2018.81004

Received: November 28, 2017

Accepted: January 16, 2018

Published: January 19, 2018

Copyright (c) 2018 by authors and Scientific Research Publishing Inc. This work is licensed under the Creative Commons Attribution International License (CC BY 4.0).

http://creativecommons.org/licenses/by/4.0/

\begin{abstract}
Grisel's syndrome is a rare complication that is characterized by non-traumatic atlantoaxial subluxation. It is most commonly seen in children after an upper respiratory tract infection or neck surgery, such as an adenoidectomy, tonsillectomy and mastoidectomy. Grisel's Syndrome is characterized by torticollis and a limited range of motion of the neck with pain. Here the authors report a case of a Malian 5-year-old girl with Grisel's syndrome following tonsillectomy. The patient's complaints were fully resolved after 2 weeks of conservative treatment.
\end{abstract}

\section{Keywords}

Atlantoaxial Subluxation, Grisel's Syndrome, Torticollis

\section{Introduction}

Grisel's syndrome is a rare complication that is characterized by non-traumatic atlantoaxial subluxation [1]. It is most commonly seen in children after an upper respiratory tract infection or neck surgery, such as an adenoidectomy, tonsillectomy and mastoidectomy [2] [3]. Grisel's syndrome is characterized by torticollis and a limited range of motion of the neck with pain. Described by Sir Charles Bell in 1830, and named after Pierre Grisel in 1930, its incidence remains unknown and cases are reported sporadically in the literature. Diagnosis is established by clinical and radiological findings. Optimal management in- 
cludes observation, the use of cervical collars and analgesics, halter or skeletal traction, and posterior fusion of $\mathrm{C} 1 / \mathrm{C} 2$. In this paper, the authors report a case of Grisel's syndrome successfully recovered with conservative treatment.

\section{Case Report}

A Malian 5-year-old girl patient was admitted to the pediatric department with swelling and pain in the neck for 2-days duration. She had a history of tonsillectomy by ENT surgeons 1 month earlier. There was no history of physical trauma. The patient was then sent to the neurosurgical department. At physical examination, the neck was deviated to the left side with restricted range of motion (Figure 1). Neurological and systemic physical examinations were normal. A computed tomography (CT) scan demonstrated rotary subluxation at C1/C2 Type I according to the Fielding and Hawkins atlantoaxial Rotary subluxation classification, with a lateral shift of the dens toward the right (Figure 2). Diclofenac potassium was given with cervical collar and the sign of torticollis improved. Her pain completely disappeared and she gained full cervical spine range of motion after 2 weeks of treatment (Figure 3).

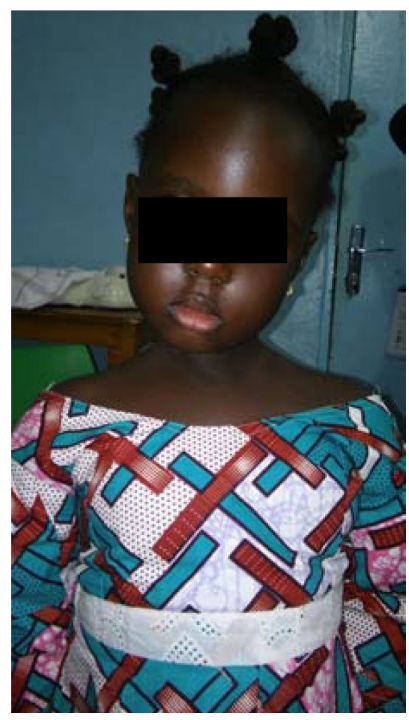

Figure 1. A 5-year-old girl with Grisel's syndrome showing painful torticollis.

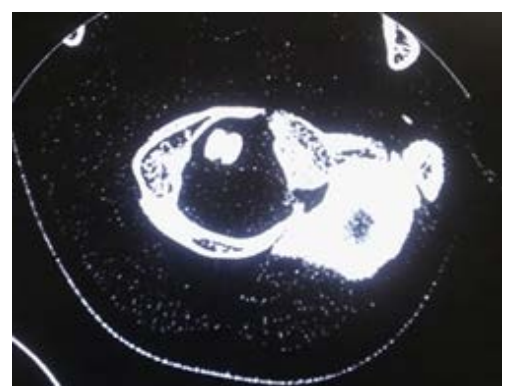

(a)

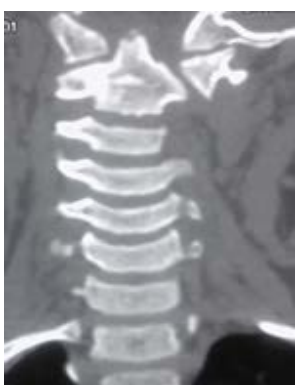

(b)

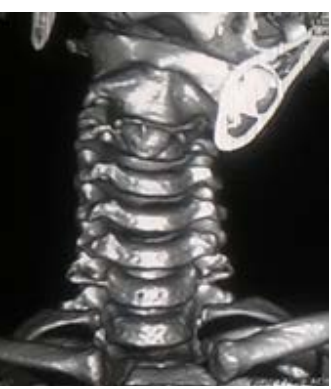

(c)

Figure 2. (a) Axial, (b) Coronal and (c) Three-dimensional reconstruction CT scans of the atlantoaxial complex. 


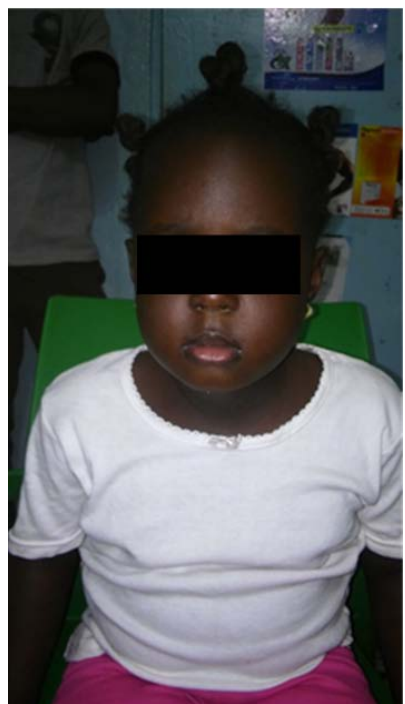

Figure 3. Photograph taken after 2 weeks of conservative treatment showing normal head posture.

\section{Discussion}

Atlantoaxial subluxation is a rare condition in which patients present with the acute onset of torticollis. Described by Sir Charles Bell in 1830, and named after Grisel syndrome in 1930 when the condition is attributable to infectious or postoperative retropharyngeal inflammation [2] [3] [4] [5]. Grisel's syndrome usually affects the pediatric population because of the anatomic differences in children when compared to adults [6]. There are different pathogenesis hypotheses, recently described by Osiro et al. [7]. The most widely accepted theory for Grisel's syndrome is the two-hit hypothesis. The first-hit is cervical ligamentous laxity seen in the pediatric population at baseline; the second-hit is the induction of spasm by inflammatory mediators carried to cervical muscles by the pharyngovertebral venous plexus [8]. History taking and clinical signs and symptoms are important in the diagnosis of Grisel's syndrome. The diagnosis is based on the presence of a new, fixed torticollis in a patient with no preexisting history of congenital muscular torticollis, significant trauma, or congenital abnormality. The patient's head is held in the classically described cock robin position with the head tilted to one side and with the chin rotated to the side opposite the facet subluxation [9]. The patient may have pain in the neck. Neurological complications occur in some cases, and may even result in death [10].

Clinical Classification of Grisel's syndrome has been based on the duration of symptoms. Ishii et al. [11] classified patients as acute when symptoms were present for $<8$ weeks; patients were classified as chronic when symptoms were present for $>3$ months. Pang and Li [12] classified patients as acute when symptoms had been present for $<1$ month, as sub-acute from 1 to 3 months, and as chronic for $>3$ months. According to these classifications our patient was classified as acute. Grisel's syndrome is primarily a clinical diagnosis. However, several imaging modalities may be useful to aid in classification, to rule out trauma 
and inflammatory conditions, and to aid in making treatment recommendations. Radiographs play a role as the initial imaging modality, mainly to rule out obvious fracture or congenital abnormality [13]. Computed tomography (CT) scan is the most helpful method in establishing the diagnosis of atlantoaxial subluxation and is integral to several classifications [9] [11] [12]. Fielding and Hawkins [9] classified Grisel's syndrome into four types based on axial CT images of $\mathrm{C} 1$ and C2 (Table 1). Type I is the most common type noted in the literature. MRI is a complementary radiological tool being able to reveal the abnormality of soft tissues and neural structures, as laxity of the transverse and alar ligaments. Optimal management for Grisel's syndrome includes observation, the use of cervical collars and analgesics, halter or skeletal traction, and posterior fusion of $\mathrm{C} 1 / \mathrm{C} 2$. The most common treatment modality in acute and Fielding's Type I and II subluxations cases include cervical collar application for comfort and rest with use of analgesics [3]. In some patients, reduction can only be achieved with cervical traction, followed by a period of neck immobilization in a cervical collar or Halo Vest for 6 weeks, to prevent recurrence of the subluxation. Fielding's Type III and IV subluxations generally need bed rest with cervical traction, followed by a period of neck immobilization. Surgical intervention with open reduction and cervical fusion is necessary in recurrent cases or when the conservative treatment has failed [14]. The patient discussed here was an acute and a Fielding's classification Type I subluxation case. Most of these cases reported in current literature have a successful outcome with a conservative treatment, including this case. In the series of Fernandez Cornejo [6], no patients needed surgery, but one patient developed permanent restriction of neck mobility. In the study by Deichmueller et al. [15], 8 of their 12 patients had full remission after conservative treatment. Four patients required reposition of the atlantoaxial joint in general anesthesia and external fixation by halo-fixation for 6 weeks.

\section{Conclusions}

In patient with painful torticollis following ENT procedures, Grisel's syndrome should be always suspected and immediate neurosurgical consultation is required.

An early diagnosis and management helps in reducing the morbidity associated with the syndrome. The conservative treatment is safe and effective, but

Table 1. Fielding and Hawkins classification of Grisel's syndrome [9].

\begin{tabular}{ll}
\hline Type I & No subluxation. Fixed rotation of atlas and axis. Anterior displacement $<3 \mathrm{~mm}$. \\
Type II & $\begin{array}{l}\text { Unilateral, atlantoaxial subluxation of one atlantoaxial joint. The contralateral joint } \\
\text { is pivotal. }\end{array}$ \\
Type III $\quad$ Ventral subluxation of C1 in both joints. Anterior displacement $>5 \mathrm{~mm}$. \\
Type IV $\quad \begin{array}{l}\text { Dorsal subluxation of C1. Combination with fractured dens axis or congenital dens } \\
\text { aplasia is possible. }\end{array}$
\end{tabular}


surgical treatment may be required when the diagnosis is delayed. The most important factor for success of conservative treatment is the time from the onset of symptoms to recognition and the initiation of treatment.

\section{References}

[1] Karkos, P.D., Benton, J., Leong, S.C., et al. (2007) Grisel's Syndrome in Otolaryngology: A Systematic Review. International Journal of Pediatric Otorhinolaryngology, 71, 1823-1827.

[2] Barcelos, A.C.E.S., Patriota, G.C. and Netto, A.U. (2014) Nontraumatic Atlantoaxial Rotatory Subluxation: Grisel Syndrome. Case Report and Literature Review. Global Spine Journal, 4, 179-186. https://doi.org/10.1055/s-0033-1363936

[3] Neal, K.M. and Mohamed, A.S. (2015) Atlantoaxial Rotatory Subluxation in Children. Journal of the American Academy of Orthopaedic Surgeons, 23, 382-392. https://doi.org/10.5435/JAAOS-D-14-00115

[4] Grisel, P. (1930) Enucléation de l'atlas et torticollis naso-pharyngien. Presse Medicale, 38, 50-54.

[5] Ombregt, L. (2013) Applied Anatomy of the Cervical Spine. In: A System of Orthopaedic Medicine, 3rd Edition, Churchill-Livingstone Publishing, London, e1-e12. https://doi.org/10.1016/B978-0-7020-3145-8.00060-0

[6] Fernández Cornejo, V.J., Martínez-Lage, J.F., Piqueras, C., Gelabert, A. and Poza, M. (2003) Inflammatory Atlanto-Axial Subluxation (Grisel's Syndrome) in Children: Clinical Diagnosis and Management. Child's Nervous System, 19, 342-347. https://doi.org/10.1007/s00381-003-0749-6

[7] Osiro, S., Tiwari, K.J., Matusz, P., Gielecki, J., Tubbs, R.S. and Loukas, M. (2012) Grisel's Syndrome: A Comprehensive Review with Focus on Pathogenesis, Natural History, and Current Treatment Options. Child's Nervous System, 28, 821-825. https://doi.org/10.1007/s00381-012-1706-Z

[8] Battiata, A.P. and Pazos, G. (2004) Grisel's Syndrome: The Two-Hit Hypothesis: A Case Report and Literature Review. Ear, Nose \& Throat Journal, 83, 553-555.

[9] Fielding, J.W. and Hawkins, R.J. (1977) Atlanto-Axial Rotatory Fixation. (Fixed Rotatory Subluxation of the Atlanto-Axial Joint). The Journal of Bone \& Joint Surgery, 59, 37-44. https://doi.org/10.2106/00004623-197759010-00005

[10] Wilson, M.J., Michele, A.A. and Jacobson, E.W. (1940) Spontaneous Dislocation of the Atlanto-Axial Articulation, including a Report of a Case with Quadriplegia. The Journal of Bone \& Joint Surgery, 22, 698-707.

[11] Ishii, K., Chiba, K., Maruiwa, H., Nakamura, M., Matsumoto, M. and Toyama, Y. (2006) Pathognomonic Radiological Signs for Predicting Prognosis in Patients with Chronic Atlantoaxial Rotatory Fixation. Journal of Neurosurgery: Spine, 5, 385-391. https://doi.org/10.3171/spi.2006.5.5.385

[12] Pang, D. and Li, V. (2005) Atlantoaxial Rotatory Fixation: Part 2-New Diagnostic Paradigm and a New Classification Based on Motion Analysis Using Computed Tomographic Imaging. Neurosurgery, 57, 941-953. https://doi.org/10.1227/01.NEU.0000181309.13211.3A

[13] Samartzis, D., Shen, F.H., Herman, J. and Mardjetko, S.M. (2010) Atlantoaxial Rotatory Fixation in the Setting of Associated Congenital Malformations: A Modified Classification System. Spine (Phila Pa 1976), 35, E119-E127. https://doi.org/10.1097/BRS.0b013e3181c9f957

[14] Crossman, J.E., David, K., Hayward, R., et al. (2003) Open Reduction of Pediatric 
Atlantoaxial Rotatory Fixation: Long Term Outcome Study with Functional Measurements. Journal of Neurosurgery. Spine, 100, 235-240.

https://doi.org/10.3171/spi.2004.100.3.0235

[15] Deichmueller, C. and Welkoborsky, H.J. (2010) Grisel's Syndrome-A Rare Complication Following "Small" Operations and Infections in the ENT Region. European Archives of Oto-Rhino-Laryngology, 267, 1467-1473.

https://doi.org/10.1007/s00405-010-1241-z 